\title{
Tekerlekli Sandalye Kullanan Sporcuların Öz Etkililik-Yeterlilik ve Başa Çıkma Stratejilerinin İncelenmesi
}

Investigation of Self-efficacy and Coping Strategies of Wheelchair Users

Şule BAYRAKTAR ${ }^{1}$, Çiğdem ÖKSÜZ ${ }^{2}$

${ }^{1}$ Ergoterpist, Hacettepe Üniversitesi Sağlık Bilimleri Fakültesi Ergoterapi Bölümü, Ankara

${ }^{2}$ Doç. Dr., Hacettepe Üniversitesi Sağlık Bilimleri Fakültesi Ergoterapi Bölümü, Ankara

\section{öz}

Amaç: Çalışmamızın amacı; tekerlekli sandalye kullanıcısı sporcular ile spor yapmayan tekerlekli sandalye kullanıcısı bireylerin öz yeterlilik düzeylerinin ve başa çıkma stratejilerinin karşılaştııılmasıdır. Gereç ve Yöntem: Bu çalışmaya tekerlekli sandalye kullanan 50 birey dahil edilmiştir. Bireyler en az 2 yıldır aktif olarak spor yapan ve spor yapmayan bireyler olarak 2 gruba ayrımıştır. Sosyodemografik bilgi formu, Öz EtkililikYeterlilik Ölçeği (ÖEYÖ) ve Başa Çıkma Stratejisi Ölçeği (BÇSÖ) kullanıımıştı. Sonuç: Spor yapmayan tekerlekli sandalye kullanan bireylerin ise yaş ortalamaları $32.9 \pm 8.99$ 'dur ve ortalama $9.55 \pm 9.75$ yıldır tekerlekli sandalye kullanmaktadır. Spor yapan tekerlekli sandalye kullanan bireyler ile spor yapmayan tekerlekli sandalye kullanan bireyler arasında ÖEYÖ alt ölçeklerinden "davranışa başlama" ve" davranışı sürdürme" alt ölçeklerinde istatistiksel olarak anlamlı fark bulunmazken; "davranışı tamamlama", "engellerle mücadele" alt ölçeklerinde ve ÖEY toplam puanında istatistiksel olarak anlamlı fark bulunmuştur $(p<0.05)$. BÇSÖ alt ölçeklerinden "sosyal destek arama" ve "kaçınma" ölçeklerinde istatistiksel olarak anlamlı fark bulunmazken; "problem çözme" alt ölçeğinde istatistiksel olarak anlamlı fark bulunmuştur $(p<0.05)$. Tartışma: Çalışmamızda sporun tekerlekli sandalye kullanan bireylerde öz yeterlilik düzeylerini ve problemlerle başa çıkma becerilerini artırdığı gösterilmiştir. Bu nedenle bedensel engelli bireylerin spor yapmaya yönlendirilmesinin onların yapıcı ve işlevsel problem çözme becerisi kazanmasına yardımcı olacağı düşüncesindeyiz. Bedensel engelli bireylerin spor yapmaya yönlendirilmesini ve bu konuda desteklenmesini önermekteyiz.

Anahtar Kelimeler: Tekerlekli sandalye; Spor; Öz etkililik-yeterlilik; Başa çıkma stratejileri

\section{ABSTRACT}

Purpose: The aim is the comparison of self-efficacy levels and coping strategies of wheelchair-bound athletes and non-sports wheelchair users. Material and Methods: 50 wheelchair user subjects were included in this study. Individuals have been divided into 2 groups as individuals who have been active in sports for at least 2 years and who do not play sports. Socio-demographic information form Self Efficacy Scale (SES) and Coping Strategy Indicator (CSI) was used. Results: The average age of wheelchair-bound athletes is $32.9 \pm 8.99$ with average $9.55 \pm 9.75$ years of wheelchair use. While there was no significant difference between "initiate behavior" and "continuing behavior" subscales of the SES subscales between wheelchair-bound athletes and non-sports wheelchair users, there was a significant difference in the subscales of "completing the behavior", "struggling with the obstacles" and the total score of SES $(p<0.05)$. While there was no statistically significant difference in the "social support search" and "avoidance" scales of the CSI subscales; statistically significant difference was found in the "problem solving" subscale $(p<0.05)$. Conclusion: In our study, sports increase the self-efficacy levels and ability to cope with problems of wheelchair users. So, we believe that directing physically handicapped individuals to do sports will help them gain constructive and functional problem solving skills. We suggest that the physically handicapped individuals should be encouraged to participate in sports.

Keywords: Wheelchair; Sport; Self efficacy; Coping strategies 
Fiziksel engelli bireyler önemli psikolojik ve sosyal anlamda problemler yaşayabilirler (Bishop, 2005). Artmış intihar düşünceleri (Pollard \& Kennedy, 2007), artmış depresyon ve anksiyete duyguları (Kewman \& Tate, 1998), düşük benlik saygısına (Manuel, Balkrishnan, Camacho, Smith, \& Koman, 2003) gibi psikolojik problemler görülebilir. Sosyal olarak, bireyler artmış olarak izolasyon ve toplumdan dışlanma duyguları hissettiklerini (Barkley, Salvy, \& Roemmich, 2012) ve aile ve arkadaşlık ilişkilerinde bozukluk hissettiklerini (Rintala, Young, Spencer, \& Bates, 1996) belirtmişlerdir.

Öz etkililik-yeterlik;" bireyin belli bir eylemi başarıyla tamamlama veya olayları kontrol edebilme algısı ya da bireyin belirli bir performans düzeyine ulaşma kapasitesine ilişkin yargısı" olarak tanımlanmaktadır (Gözüm \& Aksayan, 1999). Öz etkililik-yeterlilik kavramı ilk kez 1977 yılında Albert Bandura tarafından, "Bilişsel Davranış Değişimi" kapsamında tanımlanmıştır. Kişilerde artan bireysel yeterlilik duygusunun daha sağlıklı olma, daha yüksek başarı ve daha etkin sosyal bütünleşme ile ilişkili olduğu ileri sürülmüştür. Bu kavram akademik beceriler, emosyonel bozukluklar, mental ve fiziksel sağlık ve sosyopolitik değişim gibi pek çok farklı alanda kullanılabilmektedir (Keskin \& Orgun, 2006). Bireyin öz etkililik-yeterlik algısının, sağlığı geliştiren davranışların başlatılması ve sürdürülmesinde önemli bir etken olduğu Sağlığı Geliştirme Modeli'nde belirtilmektedir (Gözüm \& Aksayan, 1999).

Çeşitli çalışmalar başa çıkma becerisinin, engelli bireylerin mevcut durumlarına psikososyal uyum sağlamasında önemli bir değişken olduğunu göstermiştir (Adamo \& Martin, 2009; Kara \& Açıkel, 2012). Başa çıkma, mevcut durumla ilgili öznel değerlendirmelerle beraber nesnel istemlere verilen tepkinin zaman içerisinde değişmesiyle oluşan dinamik bir süreçtir (Smith 2013, McAuliff, 2017) Bununla birlikte bireyin başa çıkma becerisi içinde bulunduğu durumu değerlendirme biçimini de etkilemektedir. Başa çıkma süreklilik gösteren bir kişilik tarzından çok kişinin yaşamda karşılaştığı stres durumlarına tepki olarak gösterilen biliş ve davranışlar olarak incelenmektedir (Aysan, 2003).

Spor ve fiziksel aktivitelerin, rehabilite ve tedavi edici etkisi vardır. Spor engelli bireylerde fiziksel, zihinsel, duygusal ve sosyal gelişimi destekleme amacıyla kullanılmaktadır. Spor, engelli bireylere fiziksel aktivitelere katılım fırsatının yanı sıra kişilik gelişimi ve özgüven duygusu kazandırmakta ve toplumsal yaşama uyum göstermesi yönünde büyük kolaylık sağlamaktadır. Bununla birlikte bireylerin çevrelerindeki kişilerle ve arkadaşlarıla etkileşimleri, paylaşma ve özveri duyguları gelişerek ve kendilerine güvenleri artmaktadır (Yanlıç, 2011).

Spor ile yapılan aktiviteler engelli bireylerin yaşam kalitesini arttırmasının yanı sıra sporcu kimliği ile kendilerini gerçekleştirebilecekleri bir sosyal ortam sağlar. Engelli bireylerin hayata tutunması açısından spor engelli bireylere yaşam boyu önerilmektedir (Yanlıç, 2011). Kişiliğin gelişim sürecinde oluşan benlik algısı, kişinin kendisi hakkında düşünmesinin, kendisini algılamasının ve toplumsal bir karşılaştırma yapmasının bir sonucudur. Spor, kişilerin antrenman ve müsabakalara katılması yoluyla kişiliği etkiler ve onu yüksek performansa hazırlar (Söğüt, 2006).

Engelli bireylerin başa çıkma ve öz yeterlilik becerilerinde sorunlar yaşadığı ve sporun bireyin kişiliğine olumlu yansımaları göz önüne alındığında; çalışmamızda tekerlekli sandalye kullanıcısı sporcular ile spor yapmayan tekerlekli sandalye kullanıcısı bireylerin öz yeterlilik düzeylerinin ve başa çıkma stratejilerinin karşılaştırılması amaçlanmaktadır.

\section{GEREÇ VE YÖNTEM}

Bu çalışma Aralık 2015 - Mayıs 2016 tarihleri arasında, çalışmaya katılmaya gönüllü olan tekerlekli sandalye kullanan bedensel engelli bireyler ile yapılmıştır. Çalışmaya en az 2 yıldır tekerlekli sandalye kullanan, 18-50 yaş arasında toplam 50 birey dahil edilmiştir. Bireyler en az 2 yıldır aktif olarak spor yapan (Grup 1) ve spor yapmayan bireyler (grup 2) olarak 2 gruba ayrılmıştır. Spor yapan bireyler ile Türkiye Atıcılık Şampiyonası'nda ve Olimpiyat Hazırlık Merkezi'nde yüz yüze görüşme tekniği ile, spor yapmayan bireylerle ise online anket yoluyla ve yüz yüze görüşme tekniği ile görüşülmüştür. Çalışmaya dahil edilmeden önce bireylere açıklamalı onam formu imzalatılmıştır. Çalışma Helsinki Deklarasyonuna uygun olarak yürütüldü.

Bireylerin sosyodemografik bilgileri sorgulanmış ve Öz Etkilik-Yeterlilik Ölçeği ve Başa Çıkma Strateji Ölçeği formlarını doldurmaları istenmiştir.

Sosyodemografik Bilgi Formu: Bu form bireylerin yaş, cinsiyet, eğitim durumu, medeni durum, tekerlekli sandalye kullanım süresi, spor yapılan süre, spor dalı gibi sosyodemografik bilgilerini elde etmek amacıyla oluşturulmuştur. Sorular araştırmacılar tarafından hazırlanmıştır.

Öz Etklilik-Yeterlilik Ölçeği(ÖEYÖ): Bu ölçek ilk olarak 1982 yılında Sherer ve arkadaşları tarafından 
geliştirilmiş, Türkçe güvenilirlik ve geçerliliği 1999 yılında Gözüm ve Aksayan tarafından yapılmıştır. Ölçek herhangi bir duruma özel olmayan, genel öz yeterlilik algısını ölçmektedir. Ölçek likert tipindedir ve 23 ifadeden oluşmaktadır, en az 23 en çok 115 puan alınabilmektedir. Ölçekte, her bir madde için 1beni hiç tanımlamıyor, 2-beni biraz tanımlıyor, 3kararsızım, 4-beni iyi tanımlıyor, 5-beni çok iyi tanımlıyor, seçeneklerinden biri işaretlenmekte ve her madde için verilen puan esas alınmaktadır. Ancak 2., 4., 5., 6., 7., 10., 11., 12., 14., 16., 17., 18., 20., 22. maddeler terse döndürülerek puanlanır. Alınan toplam puanın yüksek olması, genel ÖEY algısının yüksek olduğunu göstermektedir. Ölçeğin dört alt ölçeği vardır: 1. Davranışa başlama (DB): 2., 11., 12., 14., 17., 18., 20., 22. maddeleri; 2. Davranışı sürdürme (DS): 4., 5., 6., 7., 10., 16., 19. maddeleri; 3. Davranışı tamamlama(DT): 3., 8., 9., 15., 23. maddeleri; 4. Engellerle mücadele (EM): 1., 13., 21. maddeleri içermektedir (Keskin \& Orgun, 2006).

Başa Çıkma Strateji Ölçeği (BÇSÖ): Başa çıkma Stratejisi Ölçeği (BSÖ) 1990 yılında Amirkhan tarafından geliştirilmiş ve Türkçe güvenilirlik ve geçerliliği 2003 yılında Aysan tarafından yapılmıştır. Bireylerin stres oluşturan durumlarda başa çıkma stratejilerini kullanma derecesini ölçen bir öz değerlendirme aracıdır (Aysan, 2003). Ölçek 33 maddeden oluşmaktadır, her biri 11 maddeden oluşan Problem Çözme (PÇ), Sosyal Destek Arama (SDA), Kaçınma (K) olmak üzere 3 alt ölçek içermektedir. Ölçeğin tüm maddeleri tersine çevrilerek puanlanmaktadır. Alt ölçeklerden alınan en yüksek puan 33 , en düşük puan 11 'dir ve tüm alt ölçekler için 11-16 arasındaki puanlar çok düşük, 17-21 arasındakiler düşük, 22-26 arasındakiler ortalamanın üstü, 27-33 arasındakiler yüksek puanlar olarak değerlendirilir (Aysan, 2003) (Amirkhan, 1994).

\section{İstatistiksel Analiz}

İstatistiksel analizlerde 'SPSS 16 for Windows' istatistik programı kullanılmıştır. Ölçümle belirlenen değişkenler, ortalama \pm standart sapma(X $\pm S S)$ olarak ifade edilmiş, sayımla belirlenen değişkenler için yüzde (\%) değeri hesaplanmıştır. Spor yapan tekerlekli sandalyeli bedensel engelli bireyler ve spor yapmayan tekerlekli sandalyeli bedensel engelli bireyler olarak iki grubun ÖEYÖ ve BÇSÖ sonuçlarının karşılaştırılmasında "Bağımsız Örneklem T Testi” uygulanmıştır. İstatistiksel anlamlılık düzeyi $p<0.05$ olarak kabul edilmiştir.

\section{SONUÇ}

Çalışmaya dahil edilen bireylere ait demografik özellikler Tablo 1'de verilmiştir. Bu tabloya göre tekerlekli sandalye kullanan sporculardan (grup 1) 30 bireyin 12'si kadın (\%40) ve 18'i erkek (\%60) olmak üzere yaş ortalamaları $33.5 \pm 6,1$ 'dir. Spor yapan bireyler en az 3 , en fazla 35 yıl olmak üzere ortalama $17.3 \pm 7.85$ yıldır tekerlekli sandalye kullanmaktadır. Bu bireylerden 23'ü atıcılık, 6'sı basketbol ve 1'i halter sporu ile uğraşmakta ve ortalama $8.63 \pm 4.45$ yıldır spor yapmaktadır.

Tablo 1'e göre spor yapmayan tekerlekli sandalye kullanan (grup 2) 20 bireyin 9'u kadın (\%45), 11'i erkek (\%45) olmak üzere yaş ortalamaları $32.9 \pm 8.99$ 'dur. Spor yapmayan bireyler en az 2 yıl, en fazla 40 yıl olmak üzere ortalama $9.55 \pm 9.75$ yıldır tekerlekli sandalye kullanmaktadır.

Spor yapan bireylerin Öz Etkililik-Yeterlilik (ÖEY) toplam puanları ortalaması $89.63 \pm 12.78$ olarak yüksek düzeyde bulunmuştur. ÖEY alt ölçekleri puanları ortalaması Davranışa başlama

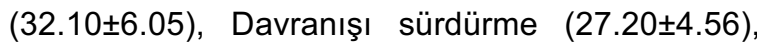
Davranışı tamamlama $(19.90 \pm 4.43)$ ölçekleri yüksek düzeyde, Engellerle mücadele (10.43 \pm 2.78$)$ olarak orta düzeyde bulunmuştur. Başa Çıkma Strateji Ölçeği (BÇSÖ) puanları ortalaması Problem çözme (28.60ะ3.37) alt ölçeğinde yüksek değerler, Sosyal destek arama $(25.73 \pm 4.81)$ ve Kaçınma (23.53 \pm 4.06$)$ alt ölçeklerinde ortalamanın üstü değerler aldığı görülmüştür (Tablo 2).

Spor yapmayan bireylerin ÖEY toplam puan ortalaması $80.95 \pm 14.40$ olarak orta düzeyde bulunmuştur. ÖEY alt ölçekleri puanları ortalaması Davranışa başlama $(30.75 \pm 6.25)$ yüksek düzeyde, Davranışı sürdürme $(25.85 \pm 4.91)$ ve Davranışı tamamlama (16.90 \pm 3.98$)$ orta düzeyde, Engellerle mücadele $(7.45 \pm 1.93)$ düşük düzeyde bulunmuştur. BÇSÖ alt ölçekleri puanları ortalaması Problem çözme (25.05 \pm 3.67$)$, Sosyal destek arama

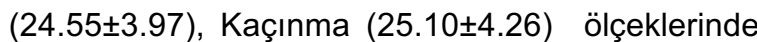
ortalamanın üstü değerler aldığı bulunmuştur (Tablo 2).

1. Gruptaki bireyler ile 2. gruptaki bireyler arasında ÖEYÖ alt ölçeklerinden davranışa başlama (p:0.450) ve davranışı sürdürme (p:0.325) alt ölçeklerinde istatistiksel olarak anlamlı fark bulunmazken ( $p>0.05)$; davranışı tamamlama (p:0.019), engellerle mücadele (p:0.000) alt ölçeklerinde ve ÖEY (p:0.030) toplam puanında istatistiksel olarak anlamlı fark bulunmuştur $(p<0.05)$.1. Gruptaki bireyler ile 2. gruptaki bireyler karşılaştırıldığında BÇSÖ alt ölçeklerinden sosyal 
destek arama (p:0.367) ve kaçınma (p:0.197) ölçeklerinde istatistiksel olarak anlamlı fark bulunmazken ( $p>0.05)$; problem çözme $(0.001)$ alt ölçeğinde istatistiksel olarak anlamlı fark bulunmuştur $(p<0.05)$ (Tablo 2$)$.

Tablo 1. Demografik Özellikler

\begin{tabular}{|c|c|c|c|c|}
\hline & \multicolumn{2}{|c|}{ Grup 1} & \multicolumn{2}{|c|}{ Grup 2} \\
\hline & $\mathrm{n}=30$ & $\%$ & $n=20$ & $\%$ \\
\hline \multicolumn{5}{|l|}{ Cinsiyet } \\
\hline Kadın & 12 & 40 & 9 & 45 \\
\hline Erkek & 18 & 60 & 11 & 55 \\
\hline \multicolumn{5}{|l|}{ Eğitim } \\
\hline İlkokul mezunu & 3 & 10 & 0 & 0 \\
\hline Ortaokul mezunu & 5 & 16.7 & 3 & 15 \\
\hline Lise mezunu & 16 & 53.3 & 9 & 45 \\
\hline Yüksekokul mezunu & 6 & 20 & 8 & 40 \\
\hline \multicolumn{5}{|l|}{ Medeni Durum } \\
\hline Bekar & 20 & 66.7 & 14 & 70 \\
\hline Evli & 10 & 33.3 & 6 & 30 \\
\hline \multicolumn{5}{|l|}{ İlgilenilen Spor Dalı } \\
\hline Halter & 1 & 3.3 & & \\
\hline Atıcılık & 23 & 76.7 & - & - \\
\hline Basketbol & 6 & 20 & & \\
\hline
\end{tabular}

Tablo 2. Öz Etkililik-Yeterlilik ve Başa Çıkma Strateji Öıçeği Puanlarının karşılaştırılması

\begin{tabular}{|c|c|c|c|c|c|}
\hline \multirow{2}{*}{$\begin{array}{c}\text { Gruplar } \\
\text { Ölçek/Alt ölçek }\end{array}$} & \multicolumn{2}{|c|}{ Grup 1} & \multicolumn{2}{|c|}{ Grup 2} & \multirow[b]{2}{*}{$p$} \\
\hline & Ort. & SS & Ort. & SS & \\
\hline \multicolumn{6}{|l|}{ Öz Etkililik-Yeterlilik Ölçeği } \\
\hline $\begin{array}{c}\text { Öz Etkililik-Yeterlilik } \\
\text { Toplam Puanı }\end{array}$ & 89.63 & 12.78 & 80.95 & 14.40 & $0.030^{*}$ \\
\hline Davranışa Başlama & 32.10 & 6.05 & 30.75 & 6.25 & 0.450 \\
\hline Davranışı Sürdürme & 27.20 & 4.56 & 25.85 & 4.91 & 0.325 \\
\hline Davranışı Tamamlama & 19.90 & 4.43 & 16.90 & 3.98 & $0.019^{*}$ \\
\hline Engellerle Mücadele & 10.43 & 2.78 & 7.45 & 1.93 & $0.000^{* *}$ \\
\hline \multicolumn{6}{|l|}{ Başa Çıkma Strateji Ölçeği } \\
\hline Problem Çözme & 28.60 & 3.37 & 25.05 & 3.67 & $0.001^{* *}$ \\
\hline Sosyal Destek Arama & 25.73 & 4.81 & 24.55 & 3.97 & 0.367 \\
\hline Kaçınma & 23.53 & 4.06 & 25.10 & 4.26 & 0.197 \\
\hline
\end{tabular}

\section{TARTIŞMA}

Çalışmamızda tekerlekli sandalye kullanan sporcuların, spor yapmayan tekerlekli sandalye kullanan bireylere kıyasla öz yeterlilik düzeylerinin ve problemle başa çıkma becerilerinin yüksek olduğu sonucuna varılmıştır.

Groff ve arkadaşlarının serebral palsili bireyler ile yaptıkları çalışmada spora katılımın, yaşamdan zevk alma, iyi hissetme, günlük yaşam aktivitelerini yerine getirme gibi davranışları olumlu etkilediği bulunmuştur (Groff, Lundberg, \& Zabriskie, 2009). Çalışmamızda tekerlekli sandalye kullanan sporcuların, spor yapmayan tekerlekli sandalye kullanıcılarına göre Davranışı Tamamlama becerileri daha etkin bulunmuştur. Gruplar arasında Davranışa başlama ve Davranışı Sürdürme alt ölçeklerinde anlamlı fark bulunmamıştır ancak spor yapan bireylerin bir eyleme ya da bir davranışa başladıktan sonra bunu tamamlamakta daha inançlı ve başarılı oldukları görülmüştür.

Greenwood ve arkadaşları tenis oynayan tekerlekli sandalye kullanıcılarının, oynamayan tekerlekli sandalye kullanıcılarına göre gerginlik, öfke, depresyon, yorgunluk ve karışıklık normlarının daha düşük olduğunu bulmuştur (Greenwood, Dzewaltowski, \& French, 1990). Tekerlekli sandalye kullanan sporcuların karşılaştıkları engellere ve durumlara verdikleri tepkiler spor yapmayan 
tekerlekli sandalye kullanan bireylere göre daha sağılılı, daha kararlı ve daha mücadelecidir. Söğüt çalışmasında bedensel engelli bireylerin sosyal yaşamda karşılaştıkları engelleri aşmasında sporun yarar sağladığını belirtmiştir (Söğüt, 2006). Çalışmamızda tekerlekli sandalye kullanan sporcuların engellerle mücadele düzeyleri literatürle uyumlu olarak daha yüksek çıkmıştır. Bedensel engellilerde sporun mücadele düzeyini artırmaya yardımcı olduğu sonucuna varmaktayız

Problem çözme kişilerin belirledikleri hedef doğrultusunda karşılarına çıkan zorlukların çözümünü bulma sürecidir (Keskin \& Orgun, 2006). Canan ve Ataoğlu yaptıkları çalışmada spor yapan bireylerin spor yapmayan bireylere göre problem çözme yeteneklerinin daha fazla olduğunu bulmuşlardır (Canan, 2010) .Spor yapmak, engelli bireylerin eksiklik duyduğu alanda desteklenerek özgüven ve benlik gelişimini sağlar ve bireylere sosyal roller kazandırır (Ergun, 2011). Çalışmamızda tekerlekli sandalye kullanan sporcuların, spor yapmayan tekerlekli sandalye kullanıcılarına göre problem çözme yeteneklerinin daha yüksek olduğu bulunmuştur. Spor yapan bedensel engelli bireylerin günlük yaşantılarında ya da belirledikleri hedefler doğrultusunda karşılarına çıkan güçlüklerle baş etme ve bu güçlükleri ortadan kaldırmaya yönelik çözüm odaklı davranışlarının daha başarıı olduğunu söyleyebiliriz.

Tekerlekli sandalye kullanıcılarının spor yapmalarının öz yeterlilikleriyle büyük ölçüde ilişkili olduğu bulunmuştur (Greenwood et al., 1990). Çalışmamızda da tekerlekli sandalye kullanan sporcuların, spor yapmayan tekerlekli sandalye kullanıcılarına göre öz yeterlilik düzeylerinin yüksek olduğu bulunmuştur. Smith'e göre kişilerin karşılaştıkları durumlarda başa çıkma becerilerini başarılı bir şekilde uygulayan bireylerin öz yeterlilik düzeyleri yüksektir (Gallagher-Thompson \& Osgood, 1998). Çalışmamızda spor yapan bireylerin problemlerle başa çıkma becerilerinin yüksek olması spor yapan bireylerin öz yeterlilik düzeylerinin yüksek olmasıyla örtüşmektedir.

Düşük öz yeterlilik duygusuna sahip bireylerde depresyon, anksiyete, çaresizlik, düşük özgüven görülür ve bu bireyler bireysel başarıları ve gelişimleri hakkında kötümser düşüncelere sahiptirler Öz yeterlilik duygusu yüksek olan bireyler başarıya gidecek olan davranışı tamamlama ve bu davranış sırasında karşısına çıkan problemleri çözme ve engellerle mücadele etmekte daha başarılıdırlar (Byrne, 2000; Maddux \& Rogers, 1983). Spor yapmanın, kişilerin bir eylemi gerçekleştirirken olayları kontrol etme ve performansını değerlendirme becerilerini arttırdığını söyleyebiliriz.

Çalışmamızda örneklem sayısının yetersizliği limitasyon olarak karşımıza çıkmaktadır. Bununla birlikte daha büyük örneklem sayısında tekerlekli sandalye kullanım süresi ve spor yapma yıllarının kategorize edildiği ayrıntılı analizlerin yapılması tekerlekli sandalye kullanım süresi ve spor yapma süresinin kişinin öz yeterlilik ve başa çıkma stratejilerine etkisini görebilmemiz açısından literatüre daha ayrıntılı bilgi sunulabileceğini düşünmekteyiz. Bunun yanında cinsiyetin başa çıkma stratejilerine etkisi düşünüldüğünde çalışmamızın cinsiyet yönünden kategorize edilmemesi de çalışmamızın bir diğer limitasyonudur.

Bedensel engelli bireylerde spor uygulamalarının bireylerin günlük yaşam aktivitelerine ve yaşam kalitelerinde önemli bir rolü vardır. Bireylerin kişilik yapılanmaları üzerine engelleriyle başa çıkabilmelerini, iletişim, sosyalleşme, eğlenme ve motivasyonla katkı sağlamaktadır (Yılmaz, Şentürk, \& Ramazanoğlu, 2014). Bu nedenle bedensel engelli bireylerin spora yönlendirilmesinin önemli olduğunu düşünüyoruz. Fakat ülkemizde gerek spor tesislerinin yetersizliği gerek fiziksel ve sosyal çevrenin olumsuzluğu nedeniyle engelli bireylerin yeterince spor yapma şansı bulamadığı bir gerçektir. $\mathrm{Bu}$ nedenle sporun engelli bireyler üzerindeki bu olumlu sonuçları göz önüne alınarak ülkemizde engelli bireylerin bu konuda desteklenmesinin gerekliliğinin bir kez daha altını çizmek istiyoruz.

\section{Kaynaklar}

Adamo, D. E., \& Martin, B. J. (2009). Position sense asymmetry. Exp Brain Res, 192(1), 87-95.

Amirkhan, J. H. (1994). Criterion validity of a coping measure. J Pers Assess, 62(2), 242-261.

Aysan, F. (2003). Başaçıkma Stratejisi Ölçeğinin Türkçe Formunun Oluşturulması. Ege Eğitim Dergisi, 3(1).

Barkley, J. E., Salvy, S.-J., \& Roemmich, J. N. (2012). The effect of simulated ostracism on physical activity behavior in children. Pediatrics, 129(3), e659-e666.

Bishop, M. (2005). Quality of life and psychosocial adaptation to chronic illness and disability preliminary analysis of a conceptual and theoretical synthesis. Rehabil Couns Bull, 48(4), 219-231.

Byrne, B. (2000). Relationship between anxiety, fear, selfesteem, and coping strategies in adolescence. Adolescence, 35(137), 201.

Canan, F. (2010). The influence of sports on anxiety, depression, and perceived problem solving ability. Anadolu Psikiyatri Dergisi, 11(1), 38-43. 
Ergun, N. (2011). Bedensel engellilerde sportif aktiviteler ve klasifikasyon. Uluslararası Katılımlı Engellilerde Beden Eğitim ve Spor Kongresi Kongre Kitabı (s. 42-47). Konya: Selçuk Üniversitesi.

Gallagher-Thompson, D., \& Osgood, N. J. (1998). Suicide in later life. Behavior Therapy, 28(1), 23-41.

Gözüm, S., \& Aksayan, S. (1999). Öz-Etkililik-Yeterlik Ölçeği'nin Türkçe formunun güvenilirlik ve geçerliliği. Journal of Anatolia Nursing and Health Sciences, 2(1).

Greenwood, C. M., Dzewaltowski, D. A., \& French, R. (1990). Self-efficacy and psychological well-being of wheelchair tennis participants and wheelchair nontennis participants. Adapt Phys Activ Q, 7(1).

Groff, D. G., Lundberg, N. R., \& Zabriskie, R. B. (2009). Influence of adapted sport on quality of life: Perceptions of athletes with cerebral palsy. Disabil Rehabil, 31(4), 318-326.

Kara, B., \& Açıkel, C. H. (2012). Predictors of coping in a group of Turkish patients with physical disability. J Clin Nurs, 21(7-8), 983-993.

Keskin, G., \& Orgun, F. (2006). Öğrencilerin öz etkililikyeterlilik düzeyleri ile başa çıkma stratejilerinin incelenmesi. Anadolu Psikiyatri Dergisi, 7(2), 92-99.

Kewman, D. G., \& Tate, D. G. (1998). Suicide in SCl: A psychological autopsy. Rehabil Psychol, 43(2), 143.

Maddux, J. E., \& Rogers, R. W. (1983). Protection motivation and self-efficacy: A revised theory of fear appeals and attitude change. J Exp Soc Psychol, 19(5), 469-479.

Manuel, J. C., Balkrishnan, R., Camacho, F., Smith, B. P., \& Koman, L. A. (2003). Factors associated with selfesteem in pre-adolescents and adolescents with cerebral palsy. J Adolesc Health, 32(6), 456-458.

Pollard, C., \& Kennedy, P. (2007). A longitudinal analysis of emotional impact, coping strategies and post-traumatic psychological growth following spinal cord injury: A 10year review. Br J Health Psychol, 12(3), 347-362.

Rintala, D. H., Young, M. E., Spencer, J. C., \& Bates, P. S. (1996). Family relationships and adaptation to spinal cord injury: a qualitative study. Rehabil Nurs, 21(2), 6790.

Söğüt, M. (2006). Sporun Bedensel Engellilerin Sosyalleşmeleri Üzerine Etkisi. Yayımlanmamış Yüksek Lisans Tezi). Mersin Üniversitesi/ Sağlık Bilimleri Enstitüsü, Mersin.

Yılmaz, A., Şentürk, U., \& Ramazanoğlu, F. (2014). Bedensel engellilerde spor konulu araştırmaların içerik analizi. Spor Yönetimi ve Bilgi Teknolojileri, 9(1-2). 